\title{
A dynamic neural model of localization of brief successive stimuli in
} saltation

\author{
Hil GE Meijer*1, Jörg Trojan², Dieter Kleinböhl2, Rupert Hölzl² and \\ Jan R Buitenweg1
}

\begin{abstract}
Address: ${ }^{1}$ Department of Mathematics, Electrical Engineering, Computer Science and Mathematics, University of Twente, Enschede, Postbus 217, $7500 \mathrm{AE}$, Netherlands and 2Otto Selz Institute for Applied Psychology, University of Mannheim, Mannheim, 68131, Germany

Email: Hil GE Meijer* - meijerhge@math.utwente.nl

* Corresponding author
\end{abstract}

from Eighteenth Annual Computational Neuroscience Meeting: CNS*2009

Berlin, Germany. 18-23 July 2009

Published: 13 July 2009

BMC Neuroscience 2009, I0(SuppI I):P350 doi:10.1 I86/I47I-2202-I0-SI-P350

This abstract is available from: http://www.biomedcentral.com//47I-2202/I0/SI/P350

(C) 2009 Meijer et al; licensee BioMed Central Ltd.

\section{Introduction}

Somatosensory saltation is an illusion robustly generated using short tactile stimuli $[1,2]$. There is a perceived displacement of a first stimulus if followed by a subsequent nearby stimulus with a short stimulus onset asynchrony (SOA). Experimental reports suggest that this illusion results from spatiotemporal integration in early processing stages, but the exact neural mechanism is unknown. The neuronal mechanism involved is probably quite generic as similar phenomena occur in other modalities, audition for example [3].

\section{Computational model}

We propose a dynamic neural field model [4] with multiple layers for localization of brief tactile stimuli. An input layer processes inputs using lateral inhibition. In addition, it sends feedforward connections to a representation layer. This layer slowly integrates incoming sensory information and computes the stored location, by means of lateral inhibition. Feedback connections finally project the model output onto a perceptual body map. Experimentally reported control of spatial attention is modeled as a bias in the receptive fields. We study how the stimulus propagates across levels in the network and how the representation of stimulus location is influenced by concurrent or successive inputs.

\section{Results}

With suitable SOA and interstimulus distance our model shows that both stimuli are spatially attracted towards each other, as observed in the saltation illusion. The range of SOAs is within the range well known from psychophysical experiments observing the saltation effect. The spatial limits in our model depend in particular on the connectivity between layers. Attention influences the midpoint between the perceived stimuli locations.

\section{Discussion}

The new computational model of a somatosensory illusion allows the design of experiments to test the underlying neurophysiological assumptions, which could lead to a further understanding of the neural mechanism(s) underlying saltation. The generic structure of the model allows application to other modalities as well (audition and nociception).

\section{Acknowledgements}

The authors received support from the 6th framework program EC project no. 043432 , Somaps.

\section{References}

I. Geldard FA, Sherrick CE: The cutaneous "rabbit": A perceptual illusion. Science 1972, I78:178-179.

2. Flach $R$, Haggard $P$ : The cutaneous rabbit revisited. J Exp Psychology: Human Perception and Performance 2006, 32:717-732.

3. Getzmann S: Saltation in pitch perception. Exp Brain Res 2006, | 79:57|-58|. 
4. Erlhagen $W$, Bastian A, Jancke D, Riehle A, Schöner G: The distribution of neuronal population activation (DPA) as a tool to study interaction and integration in cortical representations. J Neuroscience Methods 1999, 94:53-66.

Publish with Bio Med Central and every scientist can read your work free of charge

"BioMed Central will be the most significant development for disseminating the results of biomedical research in our lifetime. " Sir Paul Nurse, Cancer Research UK

Your research papers will be:

- available free of charge to the entire biomedical community

- peer reviewed and published immediately upon acceptance

- cited in PubMed and archived on PubMed Central

- yours - you keep the copyright

Submit your manuscript here:

http://www.biomedcentral.com/info/publishing_adv.asp 